\title{
"SOBRE LOS LOMOS DEL HUMOR": \\ POLISEMIA, CRÍTICA Y HUMOR EN LA POESÍA ÚLTIMA DE GLORIA FUERTES
}

VERÓNICA LEUCI

CONICET - Universidad Nacional de Mar de Plata

No son poemas, son palomas

lo que saco de mi sombrero asombrado.

Gloria Fuertes, Historia de Gloria

Los títulos de los últimos libros de la poeta madrileña Gloria Fuertes, Historia de Gloria. Amor, humor y desamor (1980) y Mujer de verso en pecho (1995), anuncian ya desde una primera aproximación, en el nivel paratextual, la temática que atañe a estas páginas: los lazos entre poesía y humorismo que atraviesan la obra de la autora y que son anticipados de manera explícita en el primero de los títulos citados, con la manifiesta inclusión del concepto "humor". Dichos lazos se formalizan retórica y discursivamente en una tendencia lúdica que recorre de manera obsesiva su poesía, no solo en esta etapa final sino también en sus poemarios iniciales, reunidos, bajo el nombre de Obras incompletas, en $1975^{2}$.

Esta propulsión lúdica es anticipada en los mencionados paratextos, como guía de lectura para los textos que nos conciernen. Por un lado, a partir de

\footnotetext{
${ }^{1}$ Este trabajo fue escrito en el marco de una Beca postdoctoral de Conicet, con sede en el Celehis, Universidad Nacional de Mar del Plata, Argentina.

${ }^{2}$ En este estudio nos centraremos en los últimos dos libros publicados en vida de la autora, corpus que constituye la etapa final de su obra: los ya mencionados Historia de Gloria. Amor, humor y desamor y Mujer de verso en pecho. Previamente, la autora reunió sus primeros poemarios, publicados entre 1954 y 1973, en las Obras incompletas, que compilan los textos Antología y poemas del suburbio (1954), Aconsejo beber hilo (1954), Todo asusta (1958), Ni tiro, ni veneno, ni navaja (1965), Poeta de guardia (1968), Cómo atar los bigotes del tigre (1969) y Sola en la sala (1973). Asimismo, es interesante señalar que la editorial Torremozas ha publicado de manera póstuma diversos libros inéditos, dentro de la Colección Gloria Fuertes: Pecábamos como ángeles (1997), Glorierías (Para que os enteréis) (2001), Es difícil ser feliz una tarde (2005), Se beben la luz (2008), Los brazos desiertos (2009) y Poemas prácticos más que teóricos (2011).
} 
la inclusión del nombre propio de la autora en el primero de ellos: esta presencia señala una de las vertientes más originales de su poesía, en la que se incorpora su antropónimo como categoría poemática, dando a luz un sujeto poético nominado que promueve la identificación con la poeta en su rol histórico, y, a la vez, explota las posibilidades de esta categoría lingüística jugando con el valor semántico de dicho nombre. Por otro lado, ambos títulos ponen en escena asimismo una línea que atraviesa su obra de manera insistente, textual y paratextualmente, apropiándose $y$, en simultáneo, renovando el acervo popular de las frases hechas, los dichos, clichés y refranes, que tanto son recuperados como invertidos o deslexicalizados en manos de la autora. En primer lugar, Historia de Gloria sugerirá los vaivenes anfibológicos en torno del nombre propio que hemos mencionado, habilitando la convivencia de "Gloria" en su carácter designativo como, a la vez, incorporando la sutil -e irónica, en un libro atravesado por la soledad, las penurias y el desamor- carga semántica de dicho vocablo, en su acepción como sustantivo común que lo equipara con "éxito" o "triunfo". Mujer de verso en pecho, en segundo lugar, resignifica el sintagma conocido y esperable, "hombre de pelo en pecho" en el desplazamiento genérico -que, inevitablemente, reenvía a la autora-, condición acentuada por el segundo trueque, el de "pelo" por "verso", que enfatiza el estatuto poético de su figuración ${ }^{3}$.

De tal forma, como decíamos, dichos sintagmas anuncian un orbe de recursos y estrategias que se solazan en las potencialidades dinámicas de la palabra poética. La poesía acudirá a diversas figuras que proponen un mundo llamativo y sorpresivo de incongruencias que trueca el horizonte de expectativas predecible para el lector. Los "juegos polisémicos" en la poesía última de Fuertes, sin embargo, conciernen no solo a un mero divertimento retórico, sino que atraviesan las múltiples caras que componen su escritura, tanto en referencia a la palabra poética, como en cuando a la configuración del sujeto y representando, por último, el prisma o la "actitud" desde la cual son representadas las diferentes temáticas y preocupaciones sociales y testimoniales -hambre, pobreza, soledad, escenarios de injusticia y opresión, etc.- que entraman, como constantes poéticas, su quehacer lírico.

En este sentido, el poema elegido como epígrafe para iluminar estas páginas, extraído del poemario de 1980, manifiesta en sus breves versos, con la imagen de la paloma, la convergencia de dos matrices complementarias: la apuesta por la paz que, sin concesiones, es proclamada en referencia a contiendas y conflictos variados y que encuentra en dicha ave su símbolo más elocuente. Sin embargo, a la vez, esta estampa mínima permite evocar el ejercicio sorpresivo de un mago que saca palomas de su "sombrero asombrado", cuestión que nos remite a la llamativa atmósfera circense que asoma a lo largo de sus páginas, poblada de personajes feriantes, arrabaleros o estrafalarios que acompañan al sujeto

\footnotetext{
${ }^{3}$ A partir de aquí, utilizaremos abreviaturas para referirnos a los libros de Fuertes que atañen a este trabajo: Historia de Gloria. Amor, humor y desamor será citado como HG, y Mujer de verso en pecho, como MVP.
} 
poético desde sus primeros libros". Asimismo, con el sintagma "sombrero asombrado", observamos por último un recurso principal y revisitado de su escritura: la paranomasia o, en sentido amplio, los abundantes -y ya anticipados- juegos lingüísticos, fónicos y semánticos que tiñen la escena con retruécanos, dilogías, silepsis, calambures y cuantiosas figuras tendientes al equívoco, la polisemia, el extrañamiento y la ambigüedad.

\section{VAIVENES POLISÉMICOS: JUEGOS LINGÜÍSTICOS Y RETÓRICOS}

La poesía de Fuertes se construye como una constelación compleja, refractaria a su inscripción en un camino unívoco y uniforme. Su producción, en cambio, se destaca por una marcada singularidad e insularidad en las letras españolas de la segunda mitad del siglo xx. Por un lado, la suya es una de las voces femeninas centrales en el acotado bloque de mujeres escritoras de la posguerra española; luego, en el panorama general de las poéticas sociales que contiene a la poeta en sus albores (en especial, por los libros reunidos en las Obras incompletas), la poesía de Fuertes se constituye a medio camino entre las dos generaciones de poetas sociales ${ }^{5}$. Por otro lado, y conjuntamente, en su poesía perviven algunos resabios del gusto humorístico que caracterizó al efímero y marginal grupo "postista" a mediados de los '40, y con el que la poeta estuvo conectada ${ }^{6}$. Por último, no podemos olvidar también el arco infantil de su pro-

\footnotetext{
${ }^{4}$ Aunque no podemos detenernos aquí en esta veta particular de la poesía de Fuertes, es menester mencionar siquiera la original inclusión de personajes asociados al mundo circense que pueblan la obra de la autora, tanto en este trayecto final como en los libros iniciales. Payasos, mimos, equilibristas, clowns, por ejemplo, junto con pregoneros, poetas callejeros, buhoneros u otros personajes excéntricos y arrabaleros (algunos de los cuales mencionaremos en este trabajo) son presencias frecuentes que acompañan al sujeto poético a lo largo de sus libros.

${ }^{5}$ La difícil ubicación de Fuertes en un grupo o generación determinada es tema que ha ocupado a la mayoría de sus críticos. Peter Browne, por ejemplo, ha realizado un estado de la cuestión al respecto, aludiendo a los múltiples autores que han discutido sobre la "productividad peculiar" de la poeta. Entre ellos, se destaca por ejemplo González Muela: "No se puede encasillar a Gloria Fuertes. No entra en ningún 'movimiento' preconcebido, ni escuela de moda; como ella dice: 'me muevo sola'. Es poeta 'social', pero no marxista; es cristiana, pero la Iglesia no la utilizaría como apologista; poeta de protesta... pero protestaría siempre que viera una injusticia; celayesca, pero en lo más hondo: en el sentido y valor que da Celaya al Hombre, no a los hombres; poetisa (odia el término), con una enorme dosis de apasionamiento y entrega, pero con un rigor masculino por limar el sentimiento o purificarlo, no explotarlo - se queda con él, como una cabra sola" (citado en Browne 1997: 5).

${ }^{6}$ La propia poeta señala su conexión con el movimiento postista que tuvo lugar en la década del '40: "fui surrealista, sin haber leído a ningún surrealista; después, aposta, 'postista' -la única mujer que pertenecía al efímero grupo de Carlos Edmundo de Ory, Chicharro y Sernesi" (2011: 27). Si bien la propensión lúdica y humorística de su poesía conecta la escritura de la poeta en sentido amplio con las características del Postismo, es importante destacar no obstante que, como señala la mayoría de sus críticos, el carácter elitista de este "ismo" tardío contraría el tenor ineludiblemente social de la pintura fuertiana. Por su lado, es interesante destacar que recientemente, en el año 2009, la editorial Torremozas ha publicado de manera póstuma el libro más explícitamente asociado a este grupo, Los brazos desiertos, escrito en 1944. Como señala Luzmaría Jiménez Faro en las "Palabras previas", el año de 1944 es crucial porque cuando de Ory y Chicharro fundan el Postismo, al que se añadirá Sernesi y que, luego, en un "ambiente divertido y bohemio iba haciendo adeptos y así, por citar algunos, se integraron en él Paco Nieva, Gabino Alejandro Carriego, Gregorio Prieto, Camilo José Cela y Gloria Fuertes" (2009: 8).
} 
ducción, extenso corpus que excede nuestros intereses actuales pero por el cual ha sido ampliamente reconocida y premiada.

Ahora bien, más allá de las múltiples aristas de su poesía, su obra se caracteriza desde sus primeros libros por un interés eminentemente comunicativo, una "obsesión de comunión-comunicación con el lector" (Fuertes 2011: 29-30). La poeta será la representante de un acontecer general, voz plural del pueblo, al que pertenece y del cual es vocera: "Lo que a mí me sucedió, sucede o sucederá, es lo que le ha sucedido al pueblo, es lo que ha ocurrido a todos, y el poeta sabe, más o menos, mejor o peor, contarlo, necesita decirlo, porque necesitáis que lo digamos" (Fuertes 2011: 23). En sus primeros textos, el foco de denuncia y testimonio lo compondrá sobre todo el contexto de la guerra civil y la posguerra; sin embargo, en sus libros finales, la poesía se proyectará también críticamente hacia el contexto social, tanto en referencia al conflicto fraticida y la dictadura franquista, como en remisión a nuevas preocupaciones y situaciones de cuño histórico-político, como la esclavitud, la bomba atómica y, de modo general, diversos azotes y penurias de carácter universal: la pobreza, el hambre, la lucha armada, etc.

La poesía de Fuertes se conecta, así, con el universo popular en estratos variados y complementarios. Así, se aboga por la constitución de una figuración popular, "juglaresca", de la poeta, posicionamiento que se abona desde sus prosas ensayísticas, desde su ejercicio literario y que se forja también en sus prolíficas actuaciones tendientes a la incidencia social: abundantes apariciones en radio y televisión, recitales de poesía, conformación del grupo "Versos con faldas" en la temprana posguerra junto con Adelaida Lasantas, María Dolores de Pablos y Acacia Uceta, creación de la primera biblioteca infantil ambulante, entre otros ${ }^{7}$.

La imagen de escritora (Gramuglio) que diseña la madrileña reafirma en el plano extratextual, empero, una cuestión que cala profundamente su escena poética y que encuentra su correlato en su poesía en diferentes niveles. Por un lado, a través de frecuentes estrategias tendientes a la oralidad, a la musicalidad. Retruécanos, paranomasias, paralelismos, anáforas, aliteraciones, formas métricas y retóricas de arte menor, uso de rima, recuperación y transformación de proverbios y paremias... Procedimientos que recorren su poética y que, a través de estas pulsiones orales, actualizan en su poesía materiales de larga data en la tradición poética española. Luego, con la inclusión de temas y personajes populares que se intercalan a la dicción poética y con los que el sujeto poético interactúa, fundiéndose como una presencia más en esa pintura realista, actuando entonces no solo como vocero sino como personaje de su obra.

En el plano formal, los abundantes juegos retóricos y discursivos actualizan en los libros que nos conciernen materiales de extensa pervivencia en las

\footnotetext{
${ }^{7}$ La autora ratifica este carácter juglaresco de su poesía, por ejemplo, al asociarla a la oralidad en pos de ensanchar al máximo el público lector, intentando sortear los límites más estrechos de la letra impresa y sus canales de circulación: "Voy por los pueblos, aldeas y provincias de España. A los que no compran libros (porque allí no llega el libro, o el dinero, o la alfabetización), yo, humildemente les llevo mi libro vivo, en mi voz, cascada rota, en mi cuerpo, cansado y ágil. Así que mi poesía también es oral, así la entiendo y me entienden" (2011: 31).
} 
letras españolas, en referencia a los cauces métricos, rítmicos, retóricos y semánticos que instauran lingüísticamente el gusto lúdico y humorístico que permite explorar al lector las posibilidades plurales del lenguaje poético. Los profusos juegos conceptistas que explotan el nivel léxico y fónico del lenguaje se observan de modo recurrente, a través por ejemplo de títulos poemáticos que acuden a figuras de dicción, como la paranomasia, el políptoton o el calambur: "Qué facha de fecha", "La oca loca", "Ejemplo ejemplar", "Estribillo sin brillo", "Menudo menú", "La saga de la soga", "Especial espacial", "Cuando la casa escasa", "El paro no hay quien lo pare", entre otros. Desde el punto de vista textual, a la vez, diversos poemas de ambos libros incorporan asimismo estos retruécanos que se deslizan por la homonimia, la dilogía y cuantiosos recursos que se regodean en el vaivén y el equívoco, instaurando la ambigüedad y la sorpresa en el lector. En HG, por ejemplo, se reemplazará el fonema "s" por " $r$ " en una de las "Autobios", para contraponer la visión realista del nacimiento a la perífrasis infantil que sustituye con frecuencia dicho suceso:

Pronto me di cuenta

que era una errata eso

de que los niños venían de París.

A los seis años cambié la ese por la erre.

Los niños vienen de Parir. (Fuertes 2004: 78. Destacado en el original)

Luego, en el mismo libro, la sustitución del fonema "u" por "e", en "Existir", dará por resultado el corrimiento hacia la versión más vulgar de la exclamación que cierra el poema: “¡Ay qué lucha, digo qué leche!" (2004: 121). Por su lado, en "Me gustaría tener una amiga", la incorporación del nombre "Tenta" renovará su valor sustantivo, para hacer convivir en el vocablo final nombre propio y adjetivo: "me gustaría tener una amiga / que se llamase Tenta. / y estar siempre conTenta" (155). Asimismo, "Títulos para futuros libros" se solazará insistentemente en la paranomasia, incluyendo sintagmas como "Blusa de Blasa. / Solo en el polo. / Garra de la guerra. / Qué asco de casco. / Cuento que encanta. / Pato a la puta..." (2004: 280). Por último, se destacan en este poemario tres propuestas singulares que ponen de relieve la importancia que se otorga al plano fónico y lingüístico de la poesía. "Carta de la Eme", "Poema de la eñe" y "Poema en ón" concentrarán en la totalidad de sus versos los fonemas o sílabas que anuncian sus títulos, respectivamente. Estos se deleitan en el divertimento de componer una carta en la que proliferan las palabras comenzadas con la letra " $\mathrm{m}$ ", en el primer caso, vocablos que incluyen la "ñ", en el segundo, y versos que eligen la rima consonante en "ón", en el último. Finalmente, MVP pondrá el acento asimismo en el valor fónico del lenguaje de la poesía, por ejemplo en el poema titulado "Gorge", en el que se acude a la dilogía en torno de "jota":

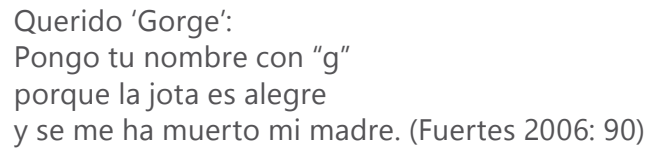


Sin embargo, sobresale especialmente en esta línea el rescate contemporáneo que se realiza en su poesía de proverbios y refranes del acervo folclórico. Esta sugestiva recuperación recorre textos y paratextos y encarna una veta novedosa -en la senda del maestro Antonio Machado- en la cual la poesía contemporánea se conecta con materiales antiguos. El uso y reapropiación de frases hechas, proverbios, sentencias, refranes o, asimismo, estructuras que remedan las formas paremiológicas, permiten dar cuenta de la revisitación de una de las fuentes más prolíficas de la sabiduría popular. Archivo profuso que, desde sus remotos orígenes, ha sido retomado por autores de todas las épocas, y cuyo gusto se destaca sobre todo en el Siglo de Oro. Amén de las colecciones y acopios castellanos de refranes realizados en tal periodo (por el precursor Marqués de Santillana, Hernán Núñez, Juan de Mal Lara, etc.), huelga mencionar el abundante uso del refranero que hace Sancho en el Quijote, por ejemplo, y asimismo grandes satíricos como Quevedo nutren sus textos con muletillas, frases hechas o, en sentido general, frases preconcebidas (en muchos casos, justamente, para parodiar o criticar estos usos "vulgares" de la lengua). También, se destaca el uso teatral del refranero en el contexto áureo: Lope, Tirso, Calderón echan mano de esta fuente, de gran arraigo en el público que llenaba los corrales de comedia, incluso apelando muchas veces a su incorporación en el título: "un recurso propio de un arte destinado a un público mayoritariamente iletrado, que se sentía 'seducido sonora y conceptualmente' por el título familiar de una pieza teatral, rótulo que formaba parte de su mundo cultural y tradicional" (Florit Durán 1984: 22-23).

Desde esta perspectiva, no es de extrañar que en la búsqueda siempre popular de la madrileña, en que se apunta a la ampliación del público lector, se recupere el copioso mundo popular del refranero y las frases hechas, con el que el lector puede sentirse próximo. Se acudirá pues pródigamente a estas expresiones a lo largo de toda su obra. En su utilización, sin embargo, se observa no solo el rescate más o menos literal de aquellos materiales sino, a la vez, la frecuente renovación y la deslexicalización de estos. Amén de los títulos de los libros a los que nos hemos referido en el inicio, múltiples poemas diseminados en ellos retoman asimismo refranes y frases tópicas del acervo tradicional, renovando en ocasiones alguno de sus términos, como destacamos a continuación: "A lo hecho pecho", "Año nuevo, piedra nueva", "No doy al César lo que del César", "Manos a la obra", son algunos de los paratextos de HG que recuperan giros precedentes. Luego, por su parte, "Va de capa caída", "Se acabó lo que se daba" o "Hablando bien y tarde" son algunas de las sentencias de MVP'.

Ahora bien, como ha advertido con lucidez Margaret Persin en su trabajo temprano "El humor como semiosis en la poesía de Gloria Fuertes", incluido en

\footnotetext{
8 Mario García-Page ha analizado con minuciosidad el uso de refranes en la poesía de Gloria Fuertes, señalando algunas tendencias principales en su incorporación. Entre ellas sobresalen: la reproducción literal, la adición de elementos extraños, la "personalización" de una paremia, creación de falsas paremias, supresión de algunos de los elementos confortantes, inversión de los signos configuradores del refrán, permutación de las dos series en refranes bimembres, sustitución lexemática o sintagmática, inclusión de refranes truncos, entre otras.
} 
su clásico libro de 1986, este primer nivel "superficial", caracterizado por los juegos de palabras, incongruencias y cambios en el nivel del lenguaje, se imbrica a un segundo nivel, que excede lo meramente textual para proponer al lector un distanciamiento intelectual, incitándolo a ver no solo la poesía sino también la realidad desde una nueva luz (1986: 150-151). De modo que, como indica la mencionada autora, "el propósito de este primer tipo de humor [...] es sorprender y captar la atención del lector" (152) en el plano lingüístico, pues "el lector ríe de los trucos, los cambios y las bufonadas del poeta" (151); pero, luego, en una operatoria que excede estos mecanismos más superficiales, en lo que Persin denomina "un segundo nivel semiótico" (159), el humor en la madrileña va más allá del texto y sugiere nuevas dimensiones interpretativas: "el humor de la poeta significa una cosa e induce a la risa, pero al mismo tiempo señala otra cosa e incita a que se consideren las cosas gastadas por el tiempo desde una perspectiva diferente" (159).

Así, el humor en Fuertes es antes que nada una actitud, una cosmovisión crítica que atañe tanto a "la vida" (la religión, el patriarcado, la política, modelos histórico-culturales, etc.) como al propio sujeto y su poesía. Los alemanes denominan Weltanschauung a esta concepción personal del mundo (Casares 1961: 29), una manera particular de ver el mundo sobre la que convergen la mayoría de los autores abocados a la temática. Como indica Fernández Flórez, por ejemplo, "el humor es, sencillamente, una posición ante la vida" (1945: 5), cuestión sobre la que discurrirá también Vilas en su estudio sobre el humor en la novela española contemporánea: "el humorista actúa movido por una actitud ante la vida, por una concepción 'sui generis' del mundo y de la vida" (1968: 53. Destacado en el original). La pulsión humorística atravesará pues la obra fuertiana en todos sus estratos: en el plano formal -exhibiendo los recodos, dobleces, contrastes y posibilidades lúdicas de la palabra poética-, en alusión a la configuración del propio sujeto, como, por último, enfocando las preocupaciones sociales y la voluntad comunicativa del ejercicio poético desde una actitud desmitificadora, burlesca, que tiñe la mirada crítica con una nueva luz antisolemne, como indica en el poema que da título a estas páginas: "Libérate de la angustia/huyendo de la quema/ sobre los lomos del humor" (2004: 77).

\section{Poeta-humorista en el diseño popular de LA Poesía}

Como decíamos más arriba, en la etapa final de su producción pervive el énfasis testimonial de su poesía. Los cuadros de pobreza, desolación, tiranía, guerra, etc. atraviesan también sus libros últimos, incluso, insistiendo en los múltiples poemas denominados "Autobio" que se incluyen en estos en las secuelas nefastas de la Guerra Civil y la posguerra, como coletazos finales de una cuestión que ganaba el centro de la escena en sus poemarios iniciales. Sin embargo, ya en el nivel paratextual, el libro de 1980 hace explícito el elemento que determinará la perspectiva desde la cual esta tendencia contestataria es enunciada: el humor.

La óptica humorística, pues, concierne tanto al plano formal como a la producción de un contradiscurso o un discurso contestatario respecto de prác- 
ticas, dogmas o costumbres dominantes. Así, como ha estudiado Pilar Monje en su valioso análisis del humor en la poesía de Fuertes, el humor en la madrileña es fundamentalmente transgresor: su objetivo es emitir un mensaje transgresor y conseguir en el lector -que se volverá, así, cómplice del sujeto humoristala aceptación de ese mensaje (2005: 479). Este carácter transgresor en Fuertes, que constituye como señalábamos su particular cosmovisión o visión de mundo, permite plantear un discurso polémico y subversivo respecto de órdenes establecidos y, la vez, invertir jerarquías, entronizando aspectos y personajes relegados o marginados del espectro social y, en su reverso, desmitificando y desacralizando posturas hegemónicas y dogmáticas. Como puede suponerse a partir de este último, el humor en Fuertes se conecta -como ha estudiado temprana y minuciosamente Sylvia Sherno (1989) - con la visión carnavalesca, sobre la que ha teorizado Bajtín. El humor evoca también, pues, el mundo popular, más específicamente, la "risa popular". Como señala el ruso en su conocido estudio dedicado a Rabelais, el humor carnavalesco, cifrado en la idea de la mencionada "risa popular", es un humor universal, es del pueblo y es ambivalente. Una de las principales cualidades de esta risa festiva es que es una risa popular ambivalente, que "expresa una opinión sobre un mundo en plena evolución en el que están incluidos los que ríen" (Bajtín 1998: 17). Esta es una de las principales diferencias con la risa satírica (negativa), cuyo autor se posiciona por fuera del mundo aludido y se opone a él; en cambio, si bien la risa popular es ambivalente -alegre pero al mismo tiempo burlona y sarcástica- es esencialmente universal, contiene a todos, incluso a los mismos burladores (Bajtín 1998: 17).

Así, bajo la óptica carnavalesca del "mundo al revés", en esta etapa tardía de la poesía fuertiana se continúa la tendencia desacralizadora y desmitificadora presente ya en sus Obras incompletas, a partir por ejemplo de géneros afines al humor, como la sátira y la parodia. El humor se apropiará pues de formas canónicas y establecidas para producir versiones innovadoras que, en todos los casos, serán repensadas y resemantizadas en diálogo con el universo popular. Es interesante destacar con Bajtín que "la parodia carnavalesca está muy alejada de la parodia moderna puramente negativa y formal; en efecto, al negar, aquella resucita y renueva a la vez" (1998: 16). De este modo, especialmente en lo que el ruso denomina "parodia sacra" (1988), se parodian a lo largo de los libros de Fuertes oraciones provenientes del culto católico, en textos como "Prez del desolado (tío o tía) de un día de sol" (HG), que parodia el rezo del Padrenuestro: "El cuerno nuestro de cada tía / dánosle hoy" (2004: 278), o en "Otra versión", del mismo libro, en que se actualiza en clave paródica y antisolemne el Génesis: "Y Adán se convirtió en manzana / y Eva se convirtió al catolicismo" (2004: 370). Asimismo, en MVP, poemas como "Diálogo del corazón de Jesús con la manita de Santa Teresa" (2006: 65), "Ángelus" (2006: 61) o "Diablito de mi guarda" se apropiarán también de rezos y discursos provenientes del rito católico para renovarlas de manera irreverente: "Diablito de mi guarda, / te comprendo y te comprendería" (2006: 33).

Es importante destacar que en este mundo popular con ribetes carnavalescos e irreverentes, la religión, Dios, lo santos y la muerte se presentan desa- 
cralizados y humanizados, como parte de un escenario que baja a las deidades de sus altares y revierte jerarquías. Dan cuenta de ello textos que aluden por ejemplo a la muerte igualadora, evocada, como ha advertido Ynduráin, sin grandes ademanes ni patetismo, sino con un singular sentido del humor y respeto, de grotesco y macabro (1979: 29). Así se observa por ejemplo en el elocuente "Epitafio de un famoso", de HG, al decir "¿Qué importa su nombre/ si aquí yace muerto el hombre?" (2004: 194), o en la visión escéptica y trivial que propone "Achaque incurable": "La muerte, / como la varicela, / es una enfermedad / que sólo te da una vez / y te inmuniza para otras muertes" (2004: 372). De esta suerte, la perspectiva desmitificadora respecto de dogmas y creencias dominantes -en este caso, la religión- se hace explícita al evocar el humor en referencia a Dios, presentándolo, pues, como sucede a lo largo de toda su obra, como un "amigo", un "compañero", desde una visión profundamente humanizada:

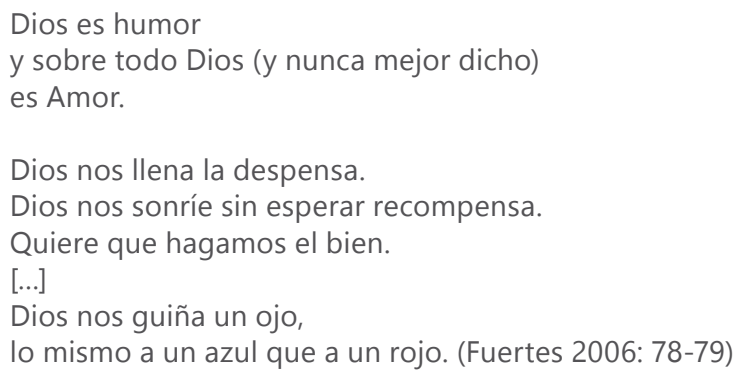

Ahora bien, esta mirada humorística se refiere también a situaciones e injusticias de índole política que se pretenden cuestionar. Esto se observa por ejemplo en "Contra la atómica", en donde se explota -continuando la tendencia anfibológica destacada anteriormente- la polisemia de las siglas "USA": "Contra la atómica, / hay que luchar sin descansar / para que la 'USA' no la vuelva a usar" (2004: 73). Por su lado, el curioso poema "El robot nazi", a través de la sátira, ridiculiza la manera de marchar de los soldados nazis y su conjunto de hábitos y maniobras característicos: "Al andar extendía las patas en línea / sin jugar con la rodilla, / el brazo derecho le alzaba bruscamente" (2004: 72). Asimismo, una estrategia recurrente en esta línea es la apropiación paródica y heteroglósica de distintas voces, discursos y géneros, a través de los cuales se logra dar testimonio o criticar situaciones diversas de desigualdad u opresión. De esta manera, se incluirán en ambos libros poemas que, desde el título, se conectan con géneros no poéticos, como el "Telegrama celestial a lugares conflictivos" y "Telegrama enviado", de HG, o los poemas "Señores importantes" y "Al señor ministro", de $M V P$, que, bajo la forma epistolar y emulando el género periodístico, envían pedidos de paz y justicia a las autoridades. Este último, por su parte, apelará a la dilogía para lograr la evidente carga irónica a propósito de la idea de "cuarto":

Señor Ministro de la Vivienda:

También desconocéis

los problemas de las familias del cuarto mundo, 
(digo cuarto mundo

porque toda la familia vive en un cuarto). (Fuertes 2006: 89)

Como ha sido mencionado más arriba, el contexto opresivo del franquismo y las secuelas de la Guerra Civil y la posguerra se harán presentes en estos textos, continuando una vertiente central de sus primeros poemarios. Aquí, las numerosas "Autobio" que se encadenan y complementan, y que poetizan datos y experiencias referidas a la vida de la poeta, aportan por ejemplo escenas que permiten traducir la atmósfera de muerte y desolación del conflicto bélico. Una de estas "Autobio", en particular, incluida en MVP, apela al humor para presentar un episodio funesto que extracta de manera irónica un "segundo nacimiento", en el relato de una experiencia traumática que es presentada, sin embargo, desde la óptica pueril de la mirada infantil:

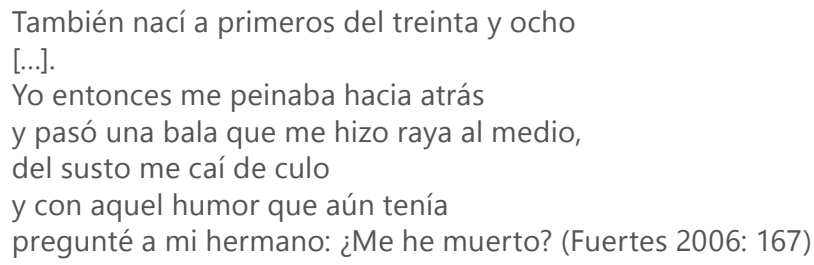

En la mención de esta original anécdota parece resonar un imaginario epocal, en donde la situación límite de la guerra y su mundo de horror y violencia son naturalizados desde la perspectiva de la experiencia privada, que tiñe sucesos aciagos con el velo mítico vinculado a la infancia. Jaime Gil de Biedma, recordemos, apuntará en su famoso "Intento formular mi experiencia de la guerra" (Moralidades) a esa "guerra al alcance los niños", por ejemplo, a partir de la "arena removida / donde estaban, sabíamos, los cinco fusilados" (1982: 131). Ángel González, a su vez, se referirá en "Ciudad cero" a "sangre descubierta / en la tierra o en las losas de la calle" o a "uno de los muchos/ prodigios cotidianos: el hallazgo/ de una bala aún caliente" (2004: 249). Si bien la poesía gloriana parece poner el acento en un tratamiento crudo y desolador de la infancia -trocando las más frecuentes imágenes idealizadas y míticas por un ambiente opresivo, plagado de injusticias, miserias y soledad-pervive en ella sin embargo la alusión a estas pequeñas "proezas", como parte de una gesta cotidiana que traduce, en clave menor, la gravedad del trasfondo bélico. Por su lado, como señala Pilar Monje en su citado estudio, más allá de la lectura metafórica que pueda hacerse de este poema, el "humor" aquí se logra a través de la trasgresión de la regla de relación con la realidad que, como hemos destacado, provoca ese efecto de "ingenuidad" en la descripción de la anécdota, asociado con la perspectiva y la trivialización infantil. Como indica la autora, "el referente del texto (una bala que peina a una niña con raya en medio) contrasta con la realidad evocada por el lector (el efecto dañino de una bala), que el verso desvirtúa" (2005: 302). Por lo tanto, en este caso, "la motivación del humor está en la irrelevancia del objeto observado con respecto a la realidad de la que forma parte" (2005: 303). 
Por último, como parte de ese mundo popular presentado desde la lupa humorística, subversiva y desmitificadora, es importante tener en cuenta que si Dios, la muerte, los santos son -como decíamos más arriba- desacralizados, en cambio, los actores y personajes más marginados del espectro social son destacados en el universo poético fuertiano. Mendigos, prostitutas, serenos, pitonisas, reos, travestis, homosexuales serán las presencias preferidas a las que, incluso, se les cede la voz, y con las que el sujeto se identifica, como parte de ese mundo arrabalero y suburbial del que forma parte. Así, la poesía rescata estas voces marginales, por ejemplo en el poema "Chica de Alterne", en donde leemos a una prostituta que, en primera persona, extracta un relato in media res de su vida, jugando entre sus proyectos y su realidad a partir de la antanaclasis. Esta escinde el significado del término "barra" como símbolo de su pasado trunco como bailarina, por un lado, y su presente de prostitución en los bares nocturnos:

\author{
Yo quería ser bailarina ¿sabe? \\ ... estudié ballet, \\ pero era muy duro para mí \\ seis horas de barra. \\ Ahora también hago barra \\ pero es otra cosa con ginebra y tíos. (Fuertes 2004: 291)
}

Por su lado, en "Canción del negro" (2004: 118), el hablante presentado paratextualmente construye una estampa representativa de la opresión que excede esta vez, empero, el contexto español: la esclavitud. Luego, en la sección "Tipos ilustres", de MVP, se apropian de la palabra poética "Tomasa la payasa", el poeta "Arturo", el "sereno", la "vieja", entre otros. Entre estos, merece especial atención el poema "La destrozona" que, junto con "Mis amigas los hombres" y "A Jenny", del mismo libro, introducen en esta etapa final el tema del amor homoerótico y el travestismo, cuestiones veladas y silenciadas, en cambio, en los poemarios escritos y publicados en el contexto represivo del franquismo: "La destrozona no destrozaba nada. / Hacía el carnaval por su cuenta [...]. Ahora lo llaman travesti, / entonces (Lavapiés zona) / lo llamaban destrozona" (2006: 183).

En este orbe ex-céntrico, hondamente popular, que sirve de escenario para la voz poética, el de "poeta" se muestra como un rostro y oficio más, con el cual el lector puede reconocerse. En Gloria Fuertes la ascendencia humilde y la infancia suburbial proyectan una imagen de poeta que habla para el pueblo, para los débiles y marginados, porque conoce sus miserias y pesares. Por eso, acudirá a la "cantera" biográfica, al incorporar su nombre de autora como parte del universo poético o abundantes referencias a su propia biografía; esta será la fuente más prolífica en el pretendido trazado humano del "personaje de poeta" que recorre la poesía, toma la palabra, y rehúye imágenes mitificadas y heroicas de escritor. Así se puede observar por ejemplo en el elocuente poema titulado "Chiste", de $H G$, en donde en clave dialógica se explicitan las claves de esta figuración que sirve como vocero, mediador, revelando desde la palabra poética la realidad: 
- ¿Para qué sirve un poeta?

-El poeta tiene que ver con el verbo ver,

con el verbo sentir y con el verbo escribir.

El poeta sirve... como unas gafas,

para que veas, hijo mío, para que veas. (Fuertes 2004: 274)

Ya desde sus primeros poemarios, la propia escritora y algunos críticos han leído en la imagen de la "cabra", utilizada en el curioso poema "Cabra sola" (Poeta de guardia), un correlato del carácter "extraño", "otro", de su figuración subjetiva, cuyos primeros versos dicen: "Hay quien dice que estoy como una cabra, / lo dicen, lo repiten, ya lo creo / pero soy una cabra muy extraña" (2011: 25). La elección de dicho animal, asociado en sus usos coloquiales con la locura, ratifica una lectura antipoética y antiheroica del yo, a la vez que será esta condición la que permita, de nuevo retomando la senda de los saberes populares, decir "la verdad", condición insoslayable de su pintura poética figurativa. La escritora alude a esta singular equiparación: "Atraída únicamente por el lenguaje popular, por el saber popular, me he agarrado varias veces al dicho 'De poetas y de locos todos tenemos un poco', y transformándolo a mi manera, vuelvo a reconocer que estoy algo 'cabra'" (2011: 25). La poeta será pues la "cabra", es decir, la "loca", imagen solidaria respecto del carácter excéntrico del poeta y la poesía que propone su escritura. En este sentido, como advierte Payeras, la idea de "locura" que maneja no parece contraponerse a la de "cordura" sino, en cambio, y de forma paradójica, a una percepción muy aguda de la realidad (2003: 120).

A la vez, otras imágenes asociadas a este tenor "estrafalario" representan además aristas diversificadas del singular carácter poliédrico de su figuración; la imagen del saltimbanqui, de la enfant terrible, o del personaje argentino "Mafalda" (Pellarolo 1991) han sido algunas presencias vinculadas al sujeto-poeta que diseña su poesía, en alusión a una curiosidad impertinente que, asociada a la sorpresa o al asombro propios de la mirada infantil, promueve a la crítica y a la reflexión. Ahora bien, en la etapa final de su producción, la imagen de la "cabra" a la que acudía en uno de sus primeros libros es desplazada explícitamente en un poema de $M V P$, titulado "Parodiándome". A partir de la llamativa operatoria inter (¿o intra?) textual que anuncia el título, se retoman y revierten en este último poemario los citados versos de "Cabra sola", para incluir una nueva figuración identitaria, que resume elocuentemente la insistente búsqueda humorística de su escritura: "Hay quien dice que soy como una cómica. / Lo dicen, lo censuran iya lo creo! / pero soy una cómica extraña / que poco actúo en el televideo" (2006: 110). Este poema tardío trueca la imagen de "locura" que alumbraba el tramo inicial de su producción, para incluir en cambio el humor -la comicidad, en este caso- como un elemento vertebrador de su escritura.

A partir de esto último, vemos que la óptica humorística que impera en el cuadro desmitificador y contestatario de la poesía de Fuertes, alcanza también al propio sujeto, como parte del mundo observado. La comicidad en Fuertes no atañerá solo a una mirada crítica respecto de los sectores de poder, o a prácticas y costumbres denostadas, sino que será en cambio un humor que alcanzará tanto al universo social como al propio sujeto, desde una luz autorreflexiva que 
subvierte y pone bajo la lupa su propia figuración, su quehacer poético y su escritura. Por su lado, en consonancia con el carácter ambivalente al que aludíamos antes, la pulsión humorística fuertiana se entrecruzará frecuentemente con la compasión o la piedad, dando como resultado un humor agridulce, al estilo de "Charlot" o "Pierrot". De esta suerte, es interesante destacar que la comicidad se imbrica a otro motor central de su obra, la ternura, en especial, por sus frecuentes asociaciones con el mundo de la infancia que presentan estos libros finales -en particular, en las múltiples "Autobios" ya mencionadas- ${ }^{9}$. De tal forma, el humor en Fuertes revierte uno de los supuestos enunciados por Bergson en su clásico trabajo de 1899, al vincularse muchas veces con la emoción. Como señala el escritor en este estudio fundamental en torno a la temática,

... lo cómico solo pude producirse cuando recae en una superficie espiritual lisa y transparente. No hay mayor enemigo de la risa que la emoción. Su medio natural es la indiferencia [...]. Lo cómico, para producir todo su efecto, exige como una anestesia momentánea del corazón. Se dirige a la inteligencia pura. (Bergson 2009: 13-14).

En cambio, el humor en la poeta se conectaría con la senda en que lo ha teorizado Fernández Flórez. Recordemos que el escritor gallego, en su conocido -y discutido- Discurso de Ingreso a la Real Academia de 1945, diferenciaba el "humor" del "sarcasmo" y la "ironía", concibiendo a las tres como flexiones distintivas dentro del orbe más amplio de la "burla". Contrastándolo con los dos primeros -a los que sumará luego la sátira- el humor será para este autor "el tono más suave del iris. Siempre un poco bondadoso [...] sin acritud, porque comprende. Sin crueldad, porque uno de sus componentes es la ternura. Y si no es tierno ni es comprensivo, no es humor" (1945: 8). Asimismo, en afinidad con el carácter universal del que nos hablaba Bajtín, se propone aquí también la búsqueda del humorista por "abarcar lo más posible de la humanidad" (8), poniendo de relieve "lo que hay de desaforado y de incongruente en nuestras acciones" (8).

Esta última cita, por su lado, pone en escena una cuestión insoslayable en los estudios en torno del humor: la incongruencia. En uno de los trabajos pioneros referidos a la problemática, Komik und Humor, de 1898, destacaba Lipps la "sorpresa y la incongruencia" como los factores claves para su teoría de lo cómico, describiendo "el sentimiento de lo cómico como la fusión entre el placer y el displacer causado por la ruptura de nuestras expectativas sobre el acontecimiento en cuestión" (Llera 2003: 5) ${ }^{10}$. Por su parte, en su ya citado estudio, Bergson proponía lo que denomina "interferencia de series" como uno de los

\footnotetext{
${ }^{9}$ Respecto de esta serie de poemas denominados "Autobio" de los dos poemarios finales de la autora puede consultarse el trabajo "Gloria Fuertes: fragmentos de una vida en verso", cuyos datos se consignan en la bibliografía.

10 Lipps observa tres gradaciones para el humor, como tres modos diversos de ver el mundo, que pueden pensarse en diálogo con la citada tesis de Fernández Flórez: en primer término, el humor humorístico (caracterizado por su optimismo y lirismo), luego, el humor satírico (que contrapone un ideal a las contradicciones del mundo) y, por último, el humor irónico (cuando un sujeto es conciente del absurdo del mundo) (Llera 2003: 5).
} 
procedimientos centrales -junto con la repetición y la inversión- de lo cómico: "una situación es cómica cuando pertenece a dos series de hechos, absolutamente independientes y se puede interpretar a la vez en dos sentidos totalmente distintos" (2009: 74), cuyo ejemplo paradigmático -como señala el autor- es el "equívoco", que nos "hace reír porque pone de relieve la interferencia de dos series independientes, fuente verdadera del efecto cómico" (Bergson 2009: 75). Por último, recordemos que Aristóteles y Cicerón aludían ya en la antigüedad a esta ruptura de expectativas con efectos risibles, desarrollada posteriormente por las "teorías de la incongruencia" (Llera 2003): el primero, en su Retórica (III), y el latino, al incluir "la recepta exspectatio entre los géneros del ridiculum: 'sed ex his ómnibus nihil magis ridetur quam quod est praeter exspectationem'" (Llera 2003: 8) ${ }^{11}$.

En Gloria Fuertes, la ruptura de expectativas y la consiguiente "sorpresa" o "asombro" que esta conlleva, se observa sobre todo a partir de estrategias discursivas que exhiben desde la retórica dicho efecto. Así, su escritura se poblará de "juegos" lingüísticos -a los que ya nos hemos aproximado-que se regodean lúdicamente en las posibilidades de la palabra poética y, muy especialmente, de llamativos y singulares juegos nominales con el nombre propio de la autora. A través de ellos, como veremos, se cuestiona y altera la idea de poeta como un yo "superior", "vate", "ego carismático" o monolíticos, "profeta", etc., anclado de modo mayoritario en el uso de la primera persona del singular a lo largo de la tradición lírica.

\section{CONTORSIONES ONOMÁSTICAS EN TORNO DEL NOMBRE PROPIO}

En uno de los ejes más atractivos de su escritura, la poeta introduce su propio nombre de autora en el orbe poético. Esta sugerente irrupción nos posiciona como lectores en el cruce de la biografía y la ficción, entre el rostro civil de la poeta y su inscripción como personaje poético. Debemos resaltar sin embargo que si esta coincidencia onomástica por un lado abona una lectura autobiográfica por la identificación entre poeta/personaje, por otro, ratifica su estatuto ficcional, a partir de abundantes desplazamientos y contorsiones gramaticales y enunciativos. A través de ellos, en múltiples ocasiones este sujeto nominado, "Gloria Fuertes", se aleja del uso previsible en el género lírico de la primera persona singular y se estaciona en la segunda o la tercera, como un "tú" o un "ella": una presencia enunciada, no enunciadora de la poesía. Y, en otros poemas, la utilización nominativa hace estallar sus alcances designativos para incorporar asimismo las múltiples acepciones de las lexías "Gloria" y "Fuertes" como sustantivo y como adjetivo, respectivamente.

El espacio de indeterminación y dualidades en torno del nombre propio se sostiene especialmente por un singular conjunto de maniobras que se conglomeran en su utilización. Estos nuevos "juegos" se manifiestan a través de

\footnotetext{
${ }^{11}$ Para una aproximación al humor y la risa en el mundo antiguo puede consultarse el estudio "El humor y la risa en la antigüedad", de Camacho (2003), consignado en la bibliografía.
} 
figuras que abonan el terreno de la polisemia, el equívoco y la ambiguitas: la silepsis (también denominada dilogía) y la antanaclasis (llamada también diáfora) que permiten problematizar la incorporación "biografista" del nombre propio. La primera consiste en la utilización de una palabra que se emplea en sentido recto y a la vez figurado, o en la que coexisten dos significados (polisémicas). La segunda, de modo próximo pero no idéntico, consiste en la repetición de dos o más palabras homonímicas en un contexto reducido, como dos vocablos con un significado diferente en cada ocasión (homónimas) (Glowicka 2002: 66).

En este sentido, el sustantivo gloria aparece en sus textos no solo como sustantivo propio sino explotando sus acepciones como sustantivo común. De acuerdo con el Diccionario de la RAE, entre sus alcances principales, este puede referir al "estado de los bienaventurados en el cielo, definido por la contemplación de Dios", o bien al "cántico o rezo de la misa en latín, que comienza con las palabras Gloria in excelsis Deo", ambas en su sentido religioso. Asimismo, su significado atañe también al "honor, la fama o la reputación resultante de buenas acciones o grandes cualidades"; y, por su parte, puede hacer referencia al "gusto o placer vehemente". Luego, el apellido "Fuertes" remite asimismo no solo a su valor como patronímico, sino que también se juega con su carga semántica, como adjetivo.

En el poemario de 1980, la esfera que incorpora sus acepciones religiosas se hace visible en múltiples textos, por ejemplo en "Como siempre" (2004: 138), "Cuando me sonrieron los chavales de las chabolas" (84), "Menú de guerra" (113), "Académica" (307) o "En la noche", que utiliza la antanaclasis para yuxtaponer los términos homónimos con significados diversos, como correlato de la autora y como nombre común, respectivamente: "(rascacielo de Madrid, piso séptimo) / la Gloria está en la gloria/ en el séptimo cielo" (323. Lo destacado es nuestro). Posteriormente, el nombre de pila reaparecerá también fusionado a su sentido religioso en textos como "Tu nombre" (2006: 139) y "Ser para ti" (141), ambos de MVP.

El texto "Autoepitafio", de $H G$, se relaciona por su lado con el venero popular a través del "dicho", en el que conviven lúdicamente, en el sintagma conocido, designación y significado, en alusión a la fama: "Me alegra poder decir / para la futura historia, / que no pasé por la tierra / sin pena ni Gloria" (2004: 364). Esta acepción se enuncia como una cuestión revisitada a lo largo del poemario: "La gloria no la busco, ya la tengo en mi nombre" (68), dice uno de los primeros textos. En la misma senda, "Por qué no me he casado" (HG), juega con la bivalencia del nombre, en este caso, a partir de su remisión que es tanto subjetiva como referente a la fama:

En el 36 tuve un novio que me quiso mucho, pero se dedicaba a la política y entre el poder y la Gloria eligió lo primero. (Fuertes 2004: 303. Lo destacado es nuestro).

Por último, el nombre propio es evocado en este mismo sentido en una de las "Autobio" del poemario de 1980, en la cual se pone de relieve de manera perifrástica, a partir de una elisión que, sin embargo, se hace explícita por el contexto poemático: "Soñé que me aplaudían / que llegué a ser mi nombre" (2004: 117). Lue- 
go, en usos menos habituales, aludirá también a la conocida canción de Umberto Tozzi, en el poema "Después de todo" (254), de HG.

Estos poemas, en los que se explotan las posibilidades del nombre propio en su utilización metafórica múltiple, difuminan las expectativas biográficas que conllevaría la irrupción textual de esta ineludible categoría lingüística; en cambio, este juego de desplazamientos y distorsiones pone de manifiesto su carácter esencialmente verbal, tiñendo las correspondencias referenciales en el horizonte de lectura con una sombra de dudas e interrogaciones, al proyectar una imagen tergiversada y polifacética del nombre como cifra de la identidad ${ }^{12}$.

Ahora bien, en una segunda constelación de estos usos nominales, el nombre propio se incorpora también en estos libros últimos a partir de una segunda o tercera persona gramatical, que objetivan a "Gloria Fuertes" como un "tú" o un "ella". En esta nueva esfera, pues, leemos en HG textos como "Dentro de mil años" (2004: 356) o el último poema del libro, "Al terminar de leer este libro", que dialoga de modo circular con el "Prologuillo" que inaugura sus páginas. En él, tras las huellas de Whitman, el último verso sentenciaba: "Esto no es un libro, es una mujer" (57). En consonancia con este texto inicial, el poemario se cierra con el nombre propio de la autora, evocado nuevamente bajo la imagen metapoética que equipara poeta/ libro:

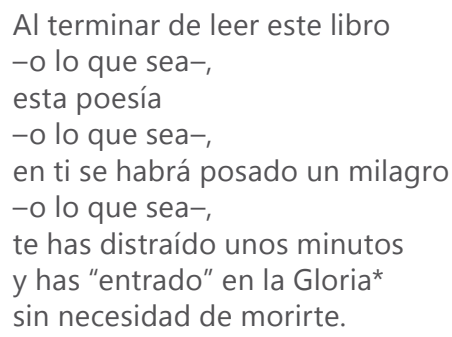

*(en la Gloria Fuertes). (Fuertes 2004: 376)

Por su lado, las frecuentes "contorsiones" gramaticales que distancian al sujeto nominado de la esfera previsible del yo acuden también a la segunda persona del singular para presentar a "Gloria Fuertes" desde un carácter dialógico, como una figura a la que se apostrofa en la poesía o que, en ocasiones, se desdobla en un diálogo consigo misma: "-¿Dónde te duele, Gloria? / -Ahí me duele, en la mismísima vida" (102), puede ser un ejemplo interesante, o también el poema "¡Qué afán!", que culmina sus reflexiones con una revelación en la que se recupera, en clave autorreferencial, el título del libro:

\footnotetext{
12 La polémica conexión entre poesía y autobiografía en la configuración de la identidad poética en la obra de Fuertes -que aquí solo puede ser mencionada sucintamente- ha sido explorada con mayor minuciosidad en mi tesis doctoral, titulada "Poetas in-versos: ficción y nombre propio en Gloria Fuertes y Ángel González", dirigida por la Dra. Laura Scarano y defendida en 2014, en la Universidad Nacional de Mar del Plata, Argentina. Respecto de esta cuestión, se recomienda la lectura de los interesantes textos de Sylvia Sherno, especialmente su libro de 2001, los capítulos compilados por Persin en su libro de 2011 y, asimismo, el artículo de Acereda (1999), todos ellos consignados en la bibliografía, abocados a estudiar y discutir los complejos lazos entre autobiografía y poesía en la poética fuertiana.
} 


\author{
Esta es vuestra historia, \\ y os recuerda Gloria, \\ que al morir perdemos todo, \\ menos la memoria. (Fuertes 2004: 362. Lo destacado es nuestro)
}

Finalmente, eligiendo solo unos cuantos ejemplos de una utilización nominal obsesiva que atraviesa sus libros, es interesante destacar la explotación lúdica que se realiza del antropónimo con la creación del neologismo "Glorierías", título del primer libro inédito publicado de manera póstuma, en el año 2001. Dicha expresión ya había aparecido antes como título poemático en $H G$, aludiendo a una sentencia breve e ingeniosa, de valor aforístico, que remeda las "greguerías" de Ramón Gómez de la Serna: "Con dinero no se puede ser todo, / por ejemplo: no se puede ser pobre" (2004: 350).

\title{
CONCLUSIONES
}

La profusa explotación semántica y gramatical de las posibilidades nominales permite advertir, en este caso, la proliferación de textos que, sin duda, contribuyen a espesar la atmósfera referencial y las suspicacias biográficas consolidadas en torno del sujeto "Gloria Fuertes". Y, a la vez, constituye uno de los elementos más sobresalientes en la tendencia anfibológica que ya ha sido mencionada, como mecanismo formal de la propensión lúdica de su obra.

Los juegos polisémicos y la óptica humorística que hemos relevado en los poemarios más tardíos de la madrileña, pues, no constituyen simplemente un mero regodeo "superficial" -al decir de Persin- por los cauces dinámicos y múltiples del lenguaje poético, en sus variados matices, trueques y desplazamientos que, en un primer nivel, conciernen a incongruencias o rupturas de expectativas en el plano fónico, morfosintáctico, etc. Dichos procedimientos, en cambio, se anudan a un universo más amplio en donde la tendencia humorística atañe también a cuestiones referidas al orden social, a discursos hegemónicos, tradiciones y creencias dominantes y asentadas, injusticias, desigualdades e, incluso, en una veta de gran originalidad de su universo poético, a la configuración del propio sujeto. En un singularísimo diseño, la identidad poética en Fuertes se aleja de visiones mitificadas o heroicas del poeta, rompiendo incluso la previsible identificación biográfica que supondría la inclusión de su nombre de autora, a partir de abundantes corrimientos y reparos que imbrican designación a connotación y abonan la escena con dudas, guiños y suspicacias más que con certezas.

Los lazos entre poesía y humorismo en los poemarios trabajados -y, en sentido amplio, en el mundo lírico de Fuertes- permiten advertir no solo un posicionamiento crítico y contestatario de la sociedad, sus personajes, costumbres, etc., sino que el humor será la perspectiva desde la que se enfoquen no solo temas revisitados sino también la propia poesía y el sujeto que esta construye. La labor del humorista, así, se conjuga a la función principal del poeta que diseñan sus versos: el énfasis comunicativo, ser vocero de los que no tienen voz. De este modo lo explicita un texto de MVP, "Difícil es echarle gracia a la desgracia", en donde -como anticipa el paratexto- se alude a la sufrida labor del humorista, que no cede en sus afanes pese a las adversidades: 
Ser humorista, peor que picar piedra,

hay que nadar al biés contra la corriente

se choca con la mueca de la gente

(que mientras todo sube

es muy difícil que la sonrisa baje)

[...].

Ser humorista es como ser cristiano.

El humorista

está en la negra lista

(he oído decir que los persiguen). (Fuertes 2006: 74)

Este sujeto-humorista convive en la poesía, como hemos visto, con nuevos hablantes. Estas figuras curiosas y arrabaleras -e, incluso, la original mención de marionetas, robots u ovnis que, sin pertenecer al suburbio, introducen igualmente notas estrafalarias- acompañan una enunciación poética que, tras una apariencia naif, solapa un humor desmitificador y carnavalesco de contornos nítidamente populares. Un pueblo que se escinde en la doble valencia de fuente y destinatario: las referencias e influencias elegidas en la poesía fuertiana se apropian -como hemos vislumbrado- casi exclusivamente del acopio tradicional, del uso del romancero, de las coplas, del refranero y de giros y expresiones coloquiales e incluso chabacanas. A la vez que, como destacamos, la poesía se dirige a un público mayoritario, como dice en el elocuente y sentencioso pareado de HG: "Un poeta no es poeta/ hasta que el pueblo nos lee" (2004: 246).

La risa imperante en la madrileña será, por último, la risa ambivalente de la que hablaba Bajtín: entre la crítica y la ternura, entre la esfera referencial y la esfera poética, entre el "ser y el no ser" -especialmente en cuanto a la construcción del sujeto nominado y su identificación con la poeta-, entre la burla y la compasión. "Humor" y "poesía" constituyen entonces -como "poeta" y "cómica"- dos caras complementarias en la propensión desmitificadora y contestataria del quehacer poético, que se emplaza bajo la luz antisolemne e irreverente del espejo elegido, en el que se reflejan -con sus sombras, claroscuros, muecas, distorsiones y matices- el hombre y el mundo.

\section{OBRAS CITADAS}

Acereda, Alberto (1999): "Autobiografía y sentido en el mundo poético de Gloria Fuertes", Letras femeninas, n. ${ }^{\circ} 25$, pp. 155-172.

— (2000): "Crítica y poesía en Gloria Fuertes. Intertextualidades culturales de una poética contestataria"., Monteagudo. Revista de Literatura Española, Hispanoamericana y Teoría de la Literatura, n. ${ }^{0}$ 5, pp. 143-157.

Aristóteles (2004): Poética. Madrid, Alianza.

Bajtín, Mijail (1981): The Dialogical Imagination. Austin, University of Texas Press.

- (1988): Problemas de la poética de Dostoievski. México, FCE.

_ (1998): La cultura popular en la Edad Media y en el Renacimiento: el contexto de François

Rabelais. Madrid, Alianza. 
Benson, Douglas (2011): "Hearing Voices: Transexuality and Heteroglosia in Gloria Fertes's Mujer de verso en pecho". En: Margaret Persin (ed.): In Her Words. Critical Studies on Gloria Fuertes. Bucknell University Press, pp. 121-137.

Bergson, Henri (2009): La risa. Ensayo sobre la significación de lo cómico. Buenos Aires, Losada.

Browne, Peter (1997): El amor por lo (par)odiado. La poesía de Gloria Fuertes y Ángel González. Madrid, Pliegos.

Camacho, Javier Martín (2003): "La risa y el humor en la antigüedad": <http://www. fundacionforo.com/pdfs/archivo14.pdf> [última visita: 22.01.2015].

Casares, Julio (1961): El humorismo y otros ensayos. Madrid, Espasa-Calpe.

Fernández Flórez, Wenceslao (1945): El humor en la literatura española. Discurso Ingreso $R A E, 14$ de mayo, pp. 1-29.

Florit Durán, Francisco (1984): "Tirso de Molina y la utilización teatral del refranero", Monteagudo, vol. 84, pp. 21-27.

Fuertes, Gloria (2011): "Prólogo" [1975]. En: Obras incompletas. Madrid, Cátedra.

— (2004): Historia de Gloria [1980]. Madrid, Cátedra. (2006): Mujer de verso en pecho [1995]. Madrid, Cátedra.

García-Page, Mario (1993): "Texto paremiológico y discurso poético (el ejemplo de Gloria Fuertes)", Paremia, n. 1 , pp. 45-53.

Gil de Biedma, Jaime (1998): Las personas del verbo [1982]. Barcelona, Lumen.

Glowicka, Monika (2002): "Figuras de repetición por juego de palabras en los eslóganes publicitarios de la prensa española actual": <http://digilib.phil.muni.cz/bitstream/ handle/11222.digilib/113033/1_EtudesRomanesDeBrno_32-2002-1_10.pdf> [última visita: 13.12.2014]

Gramuglio, María Teresa (1988): "La construcción de la imagen", Revista de Lengua y Literatura, n. ${ }^{\circ}$, noviembre, pp. 3-16.

González, Ángel (2004): Palabra sobre palabra (Obra completa). Barcelona, Seix Barral.

Jiménez Faro, Luzmaría (2009): "Palabras previas". En: Los brazos desiertos. Madrid, Torremozas, pp. 7-10.

Leuci, Verónica (2014): "Gloria Fuertes: fragmentos de una vida en verso". En: Actas al V Congreso Internacional Celehis de Literatura. Mar del Plata, UNMDP.

Lipps, Th. (1923): Los fundamentos de la Estética. Madrid, Daniel Jorro.

Llera, José Antonio (2003): "Una aproximación interdisciplinar al concepto de humor", Signa. Revista de la Asociación Española de Semiótica, n. ${ }^{\circ}$ 12. Disponible en <http:// www.cervantesvirtual.com/obra-visor/signa-revista-de-la-asociacion-espanolade-semiotica--1/html/027e2832-82b2-11df-acc7-002185ce6064_51.html> [última visita: 06.01.2015].

Monje Margelí, Pilar (2005): El humor en la poesía de Gloria Fuertes. Tesis doctoral. Universitat Rovira i Virgili. Disponible en <http://hdl.handle.net/10803/8782> [última visita: 01.12.2014].

Payeras Grau, María (2003): El linaje de Eva. Tres escritoras españolas de postguerra: Ángela Figuera, Celia Viñas y Gloria Fuertes. Madrid, Sial.

- (2009): Espejos de palabra. La voz secreta de la mujer en la poesía española de posguerra (1939-1959). Madrid, UNED. 
Pellarolo, Silvia (1991): "La poesía de Gloria Fuertes o el ingenioso distanciamiento de sí misma". En: Literatura Femenina Contemporánea. VII Simposio Internacional. Instituto Literario y Cultural e Hispánico, pp. 69-78.

Persin, Margaret (ed.) (2011): In Her Words. Critical Studies on Gloria Fuertes. Bucknell University Press.

- (1986): Poesía como proceso. Poesía española de los años 50 y 60. Madrid, Porrúa.

Sherno, Sylvia (1989): "Carnival: Death and Renewal in the poetry of Gloria Fuertes", MLN, vol. 2, pp. 370-392.

- (2001): Weaving the World: The poetry of Gloria Fuertes. University of Mississippi, Romance Monographs.

Vilas, Santiago (1968): El humor y la novela española contemporánea. Madrid, Guadarrama. Ynduráin, Francisco (1979): "Prólogo". En: Gloria Fuertes. Antología poética. 1950-1969. Barcelona, Plaza \& Janés, pp. 9-45. 